\title{
Nanomateriales integrados para el desarrollo de equipo de prevención primaria ante la COVID-19
}

\section{Integrated nanomaterials for the development of a primary prevention equipment facing COVID-19}

\author{
Rocío G. de la Torre S.*, Israel Betancourt*
}

\begin{abstract}
The interest of this review arises from the impact that COVID-19 has had worldwide. Information related to the general description of viruses is provided, up to SARS-CoV-2. These include the possible origin of the pandemic, the recommendations issued by the World Health Organization (WHO), and finally the alternatives currently available to combat SARS-CoV-2 based on the experience obtained with other viruses and bacteria. Within these options, some possible areas of application of nanotechnology are presented, as a diagnostic, treatment and/or prevention tool. Finally, the review focuses on mentioning some of the developments that have been carried out in different countries for the development of personal protective equipment (PPE) and filter material in general, as a primary prevention mechanism against viral infections. KEYWORDS: COVID-19, primary prevention, nanomaterials.
\end{abstract}

RESUMEN: El interés de esta revisión surge del impacto que ha tenido la COVID-19 a nivel mundial. Se proporcionan antecedentes relacionados con la descripción general de los virus, hasta llegar al SARS-CoV-2. Dentro de estos se menciona el posible origen de la pandemia, las recomendaciones emitidas por la Organización Mundial de la Salud (OMS), y, finalmente, las alternativas que se tienen actualmente para combatir al SARS-CoV-2 a partir de la experiencia obtenida ante otros virus y bacterias. Dentro de estas opciones, se dan a conocer algunas posibles áreas de aplicación de la nanotecnología, como herramienta de diagnóstico, tratamiento y/o prevención. Finalmente, la revisión se enfoca en mencionar algunos de los desarrollos realizados en diferentes países para la elaboración de equipo de protección personal (EPP) y material filtrante en general, como mecanismo de prevención primaria ante infecciones virales.

PALABRAS CLAVE: COVID-19, prevención primaria, nanomateriales.

\section{Antecedentes}

Los virus, como agente infeccioso, están conformados por ácido ribonucleico $(\mathrm{ARN})$ o ácido desoxirribonucleico (ADN), encapsulado en una vesícula proteica en forma de cápside, y que para su reproducción requieren de las células vivas de otros organismos. Los virus infectan a las células y usan sus componentes para autorreplicarse y, de este modo, poder invadir a más células (Carroll et al., 2016).

Recibido: 19 de mayo de 2020. Aceptado: 29 de mayo de 2020.

* Universidad Nacional Autónoma de México, Instituto de Investigaciones en Materiales, Ciudad Universitaria, Ciudad de México, México.

- Autora responsable del texto y autora de correspondencia: vinculacion@iim.unam.mx 


\section{Enfermedades virales}

Los virus pueden afectar o destruir a la célula huésped en el proceso de multiplicación. Debido a que los virus no tienen la misma biología que las bacterias, estos no pueden ser combatidos con antibióticos; solo las vacunas y/o medicamentos antivirales (Tse et al., 2020) pueden eliminar o reducir la severidad de las enfermedades que causan.

En EcoHealth Alliance, una organización dedicada a la investigación y divulgación sobre salud global, conservación y desarrollo internacional, dirigida por el Dr. Peter Daszak, se ha dedicado a identificar y predecir los orígenes y el impacto de las enfermedades emergentes en todo el mundo, entre los que se encuentra identificar cómo los murciélagos son el vector de la transmisión zoonótica (de un animal a un humano) del agente etiológico (virus del SARS-CoV) causante de la enfermedad conocida como SARS (síndrome respiratorio agudo severo). El Dr. Daszak considera que los brotes de enfermedades no solo son predecibles, sino que también se pueden prevenir, y cree que hay millón y medio de virus en la vida silvestre que aún no conocemos. ${ }^{1}$

\section{Coronavirus}

Los coronavirus ( $\mathrm{CoV}$ ) pertenecen a la familia Coronaviridae. Su genoma es de aproximadamente $30 \mathrm{kD}$, el genoma más grande entre los virus de ARN, es monocatenario en sentido positivo. Tiene un diámetro entre 80 y $60 \mathrm{~nm}$, con proyecciones superficiales (espigas) de 12 a $24 \mathrm{~nm}$, que en conjunto le dan la apariencia de corona, como se esquematiza en la figura 1 . Su genoma codifica cuatro o cinco proteínas estucturales: (espiga (S), de envoltura pequeña $(\mathrm{E})$, de membrana $(\mathrm{M})$, de nucleocápside $(\mathrm{N})$; y a veces una proteína hemaglutinina-esterasa (HE), un número variable de marcos de lectura abiertos dispersos entre los genes estructurales y una poliproteína que se procesa en múltiples proteínas no estructurales. Estas proteínas no estructurales son las que participan en la replicación del virus. El género Coronavirus se puede subdividir en grupos en función de sus propiedades genéticas y serológicas: alfa, beta, gamma y deltacoronavirus. Se han identificado 7 especies que infectan a humanos (Messel et al., 2012; Weiss y Leibowitz, 2011), denominados $\mathrm{CoV}$ humanos (HCoV). El 229E y NL63 pertenecen al género alfacoronavirus o grupo 1; OC43, HKU1, MERS-CoV, SARS-CoV y SARSCoV-2 pertenecen al género betacoronavirus o grupo 2 (MacLachlan y Dubovi 2011; Stephen et al., 2012) .

\section{Posible origen del virus SARS-CoV-2}

Los virus se clasifican de bajo a alto riesgo en función de su similitud con los que ya han infectado a humanos. En 2013, Biao He et al. describieron un virus que, aunque se habían identificado muchos coronavirus similares a los

\footnotetext{
${ }^{1}$ https://www.ecohealthalliance.org/personnel/dr-peter-daszak
} 
Figura 1. Representación de la estructura del coronavirus.

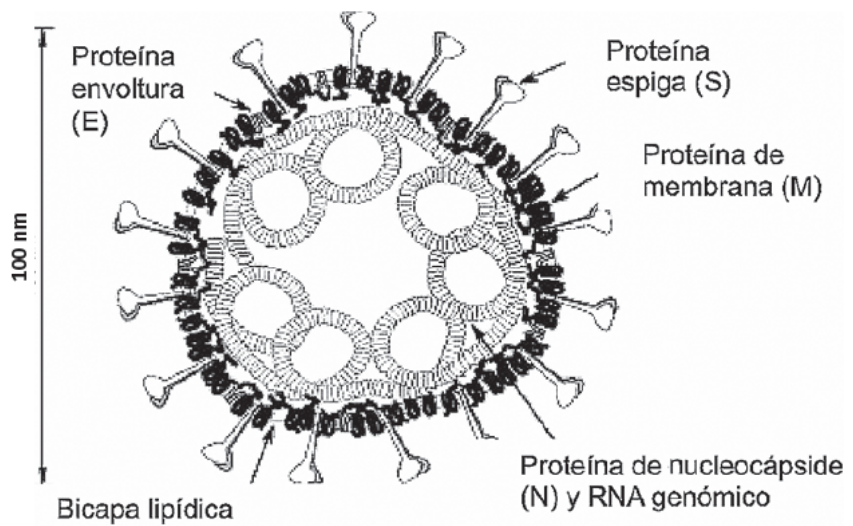

Fuente: Tomada y adaptada de Masters (2006).

causantes de SARS en China, Europa y África, la mayoría tenían una organización genética significativamente distinta, resultó en su incapacidad para causar infecciones en humanos (bajo riesgo). Sin embargo, mencionan que Yunnan, China, es una región con una alta presencia de murciélagos portadores de diversos coronavirus que podrían dar origen a la recombinación entre diferentes cepas, lo cual podría tener graves implicaciones para la salud pública. Los coronavirus causantes del síndrome respiratorio agudo severo (SARS-CoV) y el síndrome respiratorio del Medio Oriente (MERS-CoV) detonaron una nueva era en la transmisión de enfermedades respiratorias graves en especies cruzadas, y debido a la globalización se propaga rápidamente por todo el mundo (Menachery et. al., 2015).

Se han presentado muchas hipótesis que implican recombinación, convergencia y adaptación para sugerir una probable vía evolutiva para el SARS$\mathrm{CoV}-2$, pero ninguna está respaldada con evidencia directa. Este pudo haber mutado en otro murciélago, o saltó a otra especie antes de saltar al humano, como el pangolín, o una serpiente o un pescado. Como fue el caso del H1N1, resultado de la combinación del virus proveniente de un pollo y un virus proveniente de humano que mutó en un cerdo. En un momento se propuso a algunos tipos de serpientes como posibles portadores del SARS-CoV-2 ( Ji, Wang, Zhao, Zai y Li, 2020). Pero esta hipótesis ha sido ampliamente criticada al no haber evidencia de que las serpientes puedan ser infectadas y/o servir de huésped para este virus, de hecho, no hay evidencia de la infección de coronavirus a células de huéspedes que no sean mamíferos y/o aves ( $\mathrm{Ca}$ llaway y Cyranoski, 2020; Cui, Li y Shi, 2019). Días previos a los primeros contagios en Wuhan, China, a finales del mes de octubre del 2019, se reportó la presencia de un virus tipo SARS en dos pangolines malayos, los cuales habrían muerto por fibrosis pulmonar (Liu, Chen y Chen, 2019). Este virus 
Pangolín-CoV (Tsan-Yuk et al., 2020) presenta un 91.02\% de identidad genómica con el SARS-CoV-2, pero es menor que el RaTG13 de los murciélagos con similitud de 96\%, clasificado previamente con criterio de bajo riesgo (T. Zhang, Wu y Zhang, 2020). Por lo tanto, el murciélago parece ser el principal portador de los coronavirus SARS-CoV, MERS y SARS-CoV-2. La identificación del animal portador que transmitió el coronavirus a humanos es de suma importancia para la toma de decisiones en materia de salud pública.

En ese sentido, las tasas de contagio y mortalidad son indicadores epidemiológicos básicos para evaluar una pandemia. La tasa de mortalidad se define como la proporción de defunciones por una causa concreta en un periodo determinado en una población específica (número de muertes/1000 personas). Por otra parte, la tasa de letalidad es la proporción de defunciones entre los afectados por una enfermedad (número de muertes/número de casos diagnosticados) x 100. Y, la proporción de contagio es el número esperado de casos secundarios que un infectado puede generar durante su periodo de infección en una población susceptible antes de que el enfermo se recupere o fallezca. Para ejemplificar lo anterior, la pandemia de influenza entre 1918 y 1919 infectó a una de cada tres personas en el planeta; muriendo entre el 3 y el 20\% de los infectados (Humphreys, 2018). En cambio, el virus del ébola ocasiona efectos más severos en las personas contagiadas y genera una mayor tasa de mortalidad, pero una menor tasa de contagio. En las gráficas 1 y 2 se presentan las tasas de contagio y de mortalidad de diversos virus, incluyendo al SARS-CoV-2 causante de la enfermedad COVID-

Gráfica 1. Tasa de contagio (R0) de diferentes virus. Número de personas sanas a las que un paciente infectado puede transmitir el patógeno.

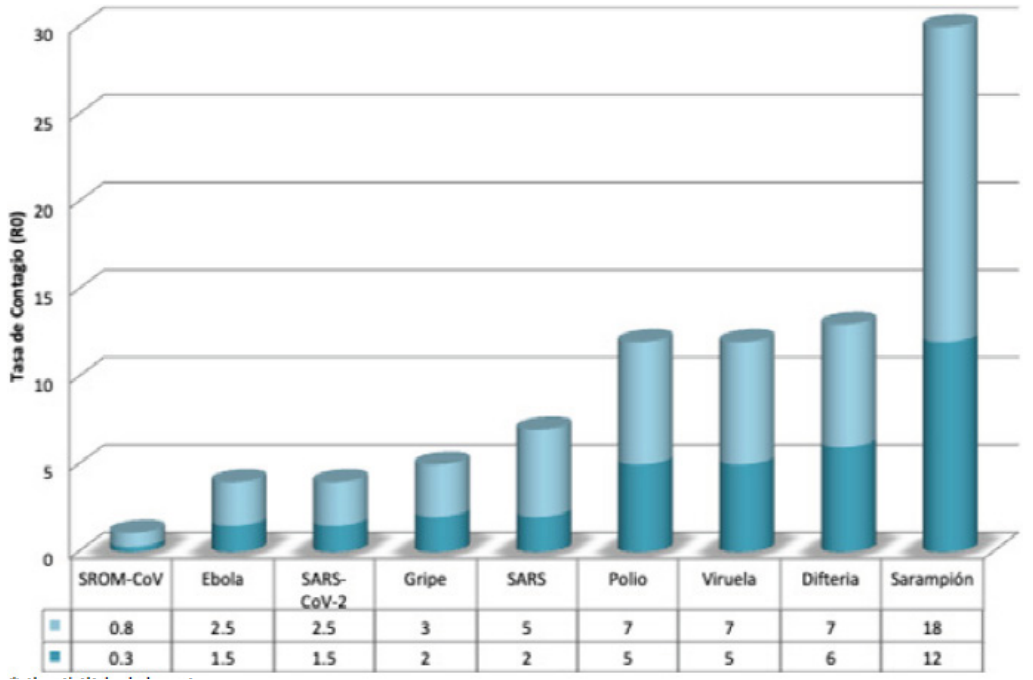

Fuente: Tomada y adaptada de Pulido (2020). 
Gráfica 2. Tasa de mortalidad (\%) de diferentes virus.

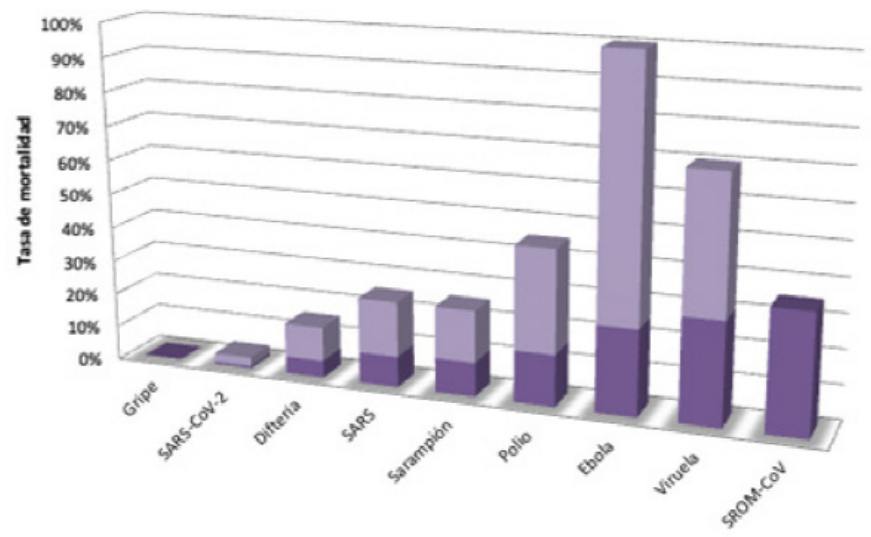

\begin{tabular}{|c|c|c|c|c|c|c|c|c|c|}
\hline & Gripe & SARS-COV-2 & Difteria & SARS & Sarampión & Polio & Ebola & Viruela & SROM-COV \\
\hline " & & $2.50 \%$ & $10 \%$ & $16 \%$ & $15 \%$ & $30 \%$ & $90 \%$ & $40 \%$ & \\
\hline = & $0.10 \%$ & $0.70 \%$ & $5 \%$ & $9 \%$ & $10 \%$ & $15 \%$ & $25 \%$ & $30 \%$ & $35 \%$ \\
\hline
\end{tabular}

Fuente: Tomada y adaptada de Organización Mundial de la Salud y Centros para la Prevención y el control de las Enfermedades (2020).

19. Los coronavirus han causado dos pandemias a gran escala en las últimas dos décadas, el SARS entre 2002 y 2003; y el síndrome respiratorio del Medio Oriente (MERS) en 2012.

\section{Origen de la pandemia actual 2019-2020}

Uno de los datos para identificar el origen del SARS-CoV-2, el South China Morning Post (Ma, 2020), reportó que el primer caso confirmado de COVID-19 ocurrió el 17 de noviembre del 2019 en la provincia de Hubei en Wuhan, China. El mercado Huanan, en Wuhan, es uno de los principales lugares considerados como tal, y donde se encontraban los murciélagos portadores del coronavirus (Andersen et al., 2020; Wu et al., 2020; Zhou et al., 2020). Es importante mencionar que en este mercado no se vendían murciélagos (Wu et al., 2020). Adicionalmente, de acuerdo con la revista científica The Lancet, en diciembre de 2019, un paciente con COVID-19 fue hospitalizado y parece no haber tenido ningún tipo de contacto con el mercado (Huang et al., 2020).

El 31 de diciembre de 2019, se informó a la Oficina de la Organización Mundial de la Salud (OMS) en China de varios casos de neumonía de etiología desconocida detectados en la ciudad de Wuhan, provincia de Hubei (China). El 9 de enero de 2020, las autoridades chinas reportaron que la causa de esta neumonía viral fue generada por un nuevo tipo de HCoV. El 11 de marzo de 2020, la OMS informó de la existencia de más de 118,000 casos de personas con COVID-19 en 114 países, y que 4,291 personas habían perdido la vida. Declarando entonces a la COVID-19 como una pandemia. 


\section{Recomendaciones de la OMS ante la amenaza de las infecciones virales}

La OMS emitió en 2005 el Reglamento Sanitario Internacional (International Health Regulations, IHR), ${ }^{2}$ relacionado con la respuesta de salud pública que se espera tener ante una crisis como la que actualmente atravesamos este año de 2020. En el artículo 5 del Título II, se establece que los países deberían desarrollar la capacidad de detectar brotes. Por otro lado, en la publicación El mundo en riesgo, del Informe anual sobre preparación global para emergencias sanitarias, de septiembre de 2019, de la Junta de Monitoreo de Preparación (Global Preparedness Monitoring Board, GPMB, 2019) de la OMS, se menciona que entre 2011 y 2018, la OMS identificó 1,483 eventos epidémicos en 172 países. En el capítulo "Preparándose para lo peor", dentro del apartado "Progreso, desafíos y acciones", se menciona lo siguiente:

Una pandemia de rápida propagación debido a una enfermedad respiratoria letal causada por un patógeno (ya sea naturalmente emergente o accidentalmente o liberado deliberadamente) requiere una preparación adicional. Teniendo como retos u obstáculos a vencer lo siguiente: No hay suficiente inversión en I + D y planificación innovadora en el desarrollo y fabricación de vacunas, antivirales de amplio espectro, intervenciones no farmacéuticas apropiadas, terapéutica dirigida (incluyendo anticuerpos monoclonales), sistemas para compartir secuencias de cualquier nuevo patógeno y medios para compartir equitativamente contramedidas médicas limitadas en todos los países. Además, tal pandemia requiere planificación anticipada en múltiples sectores (financiero, seguridad, transporte, logística, comunicaciones globales e industria), para el refuerzo social cohesión y para la comunicación de riesgos.

En términos generales, la mejor manera de vencer un virus es a través de la inmunidad. Cuando los virus se propagan por una población, algunas de las personas infectadas fallecen, pero otros sobreviven. Sus sistemas inmunológicos han aprendido a reconocer el virus y a combatirlo. Cuando esto sucede en suficientes personas, es más difícil que el virus se propague. Esto se llama inmunidad de grupo. La tasa de infección se ralentiza y el virus desaparece (Regalado, 2020). La creación de la vacuna es crucial, pero conseguirla puede tardar entre 1 y 1.5 años. Mientras tanto, lo más seguro es la cuarentena o el distanciamiento social para evitar que el virus tenga más posibilidades de propagarse. Si partimos de estos antecedentes, ¿qué alternativas tenemos antes las enfermedades infectocontagiosas?, ¿el tratamiento o la prevención?

\footnotetext{
${ }^{2}$ https://www.who.int/ihr/publications/9789241580496/en/
} 


\section{Aplicación de la nanotecnología para diagnóstico, tratamiento y prevención}

\section{Fisiopatología del SARS-CoV-2}

Para poder definir el tratamiento o medida de prevención (Vignolo et al., 2011) ante una enfermedad, es indispensable conocer su fisiopatología. Los coronavirus se unen a las células a través de formas acetiladas de glucoproteínas y lípidos; sin embargo, para que se produzca la infección viral, se requiere una unión más específica entre el virus y un receptor celular.

En el caso de la COVID-19, la glucoproteína que conforma los picos de la corona del virus SARS-CoV-2 permite que el virus se acople y se una a las proteínas de superficie ACE2 de las células epiteliales humanas, como se muestra en la figura 2. Además de la unión a los receptores antes mencionados, un segundo mapeo de factores en la proteína $S$ (posiblemente, un segundo sitio de unión al receptor) se ha implicado en el tropismo del coronavirus (Anderson et al., 2012).

Los coronavirus infectan las células epiteliales del tracto respiratorio, el tracto gastrointestinal y los tejidos nerviosos, pero también pueden verse afectados otros órganos, como el hígado, los riñones, el corazón y los ojos. El virus se replica en el tracto respiratorio inferior, seguido de una respuesta inmune innata y específica, y tanto los factores virales como la respuesta inmune (por ejemplo, la desregulación de citoquinas) contribuyen a la patogénesis. La primera etapa de la enfermedad se asocia con daño alveolar difuso, infiltración de macrófagos y células T, y proliferación de neumocitos tipo 2 . El infiltrado pulmonar aparece irregular en la radiografía de tórax. En la segunda etapa, ocurre la diseminación

Figura 2. ¿Cómo ingresa el virus SARS-CoV-2 a las células?

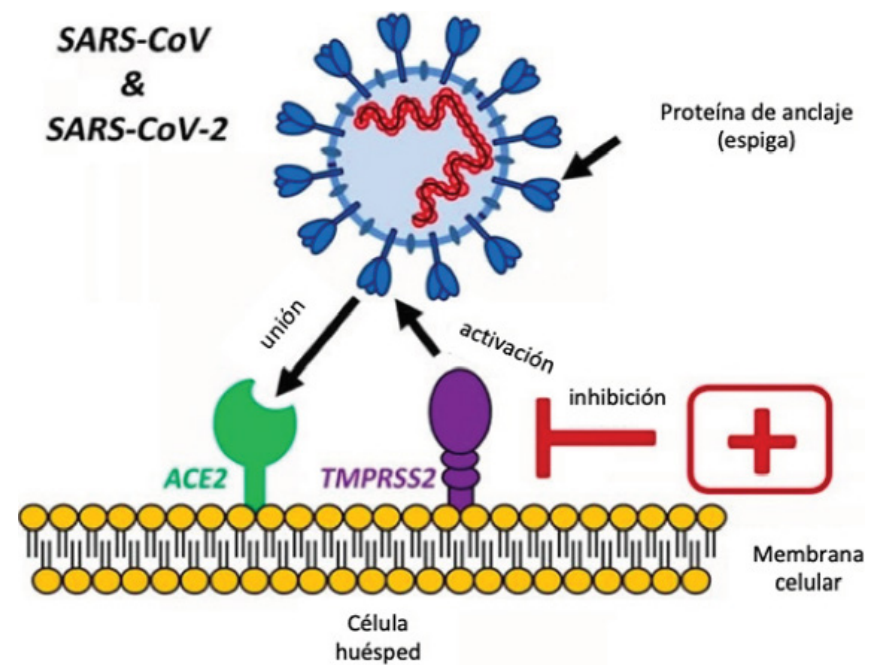

Fuente: Tomada y adaptada de Hoffmann et al. (2020). 
del virus y la infección no se limita al sistema pulmonar. Debido a que las células de sangre periférica del linaje mieloide pueden infectarse por $\mathrm{HCoV}$, estas células actúan como un vector para la propagación del virus hacia los tejidos neurales. Además, el virus se replica en los enterocitos, lo que resulta en diarrea, y se elimina en las heces, así como en la orina y posiblemente en otros fluidos corporales (Stephen et al., 2012). Además de las células epiteliales, el epitelio de las vías respiratorias posee una elaborada red de células dendríticas (DCs). Las DCs sirven como centinelas en el tracto respiratorio, donde detectan a los patógenos inhalados mediante el reconocimiento de patrones moleculares asociados a patógenos (PAMP), por ejemplo, lipopolisacáridos bacterianos o ácidos nucleicos virales. Estos receptores inducen la migración de DCs a los ganglios linfáticos drenantes y su maduración en células presentadoras de antígeno. Este proceso de maduración determina la capacidad de las DCs para estimular una respuesta inmune adaptativa contra los antígenos que han sido capturados en los pulmones. Sin embargo, alteraciones propias de diferentes factores de riesgo (diabetes, hipertensión, obesidad, etc.), afectan en la inmunidad innata y adaptativa, provocando mayor disposición a la infección y progresión a cuadros más graves y severos. Por lo tanto se requiere ahondar en los mecanismos inmunológicos que predisponen a la infección para establecer blancos terapéuticos. Además de ser indispensable poder contar con una vacuna capaz de generar la producción de anticuerpos neutralizantes del virus, se requiere disponer de equipo adecuado de protección o de barrera (Huang et al., 2020) para bloquear la entrada del virus al organismo; así como mecanismos de tratamiento (Ledford, 2020).

\section{Tratamiento y prevención de la COVID-19 mediante la nanotecnología}

En el caso del tratamiento, la aplicación de las nanopartículas está fundamentada en que el SARS-CoV-2 posee una escala similar. Thomas Webster, de la Universidad Northeastern (Molar, 2020), ha propuesto que partículas de tamaños similares que podrían unirse a los virus SARS-CoV-2 interrumpirían su estructura con una combinación de tratamiento con luz infrarroja. Ese cambio estructural detendría la capacidad del virus para sobrevivir y reproducirse. A esta práctica se le conoce como theranostics, por combinar la terapia (therapy) y el diagnóstico (diagnostic). El reto es desarrollar nanopartículas que atraigan a los virus y los inactiven; sin embargo, estas moléculas pueden también dañar otras células del cuerpo. Webster ha sugerido la utilización del óxido de hierro, debido a su presencia natural en los alimentos. Las nanopartículas con base de hierro podrían ser dirigidas mediante campos magnéticos hasta un órgano específico en el cuerpo, como los pulmones y otras áreas susceptibles a complicaciones respiratorias; el reto es que estas nanopartículas no migren al cerebro o a los riñones.

\section{Equipo de prevención primaria}

La prevención es un objetivo prioritario en los sistemas sanitarios (Terris, 1990). La aplicación de medidas preventivas puede reducir la aparición de las 
infecciones en un 32-33\%. La prevención se define como las medidas destinadas no solamente a prevenir la aparición de la enfermedad, tales como la reducción de factores de riesgo, sino también a detener su avance y atenuar sus consecuencias una vez establecida (Leavell y Clarck, 1976: 17). Las actividades preventivas se pueden clasificar en tres niveles: Prevención primaria, que se refiere a las estrategias dirigidas a prohibir o disminuir la exposición del individuo al factor nocivo; evitando la aparición de una enfermedad o problema de salud (OMS, 1998; Colimón, 1978). El objetivo de las acciones de prevención primaria es disminuir la incidencia de la enfermedad. Prevención secundaria: está destinada al diagnóstico precoz de la enfermedad incipiente (sin manifestaciones clínicas). Prevención terciaria: se refiere a acciones relativas a la recuperación de la enfermedad clínicamente manifiesta, mediante un correcto diagnóstico y tratamiento; así como la rehabilitación física, psicológica y social, en caso de invalidez o secuelas buscando reducir de este modo las mismas.

En este sentido, todo el personal involucrado en la atención médica y hospitalaria debe usar de forma rutinaria elementos de barrera cuando es posible anticipar el contacto de la piel y las membranas mucosas (boca, nariz y ojos) con sangre o fluidos biológicos de cualquier paciente. Las mascarillas (quirúrgica y de alta eficiencia), gafas o pantallas faciales deben usarse durante las operaciones en las que es probable que se generen gotículas de sangre y/o fluidos biológicos para prevenir la exposición de mucosas. En el caso particular de la COVID-19, dada su alta tasa de contagio, el desarrollo de materiales específicos para la fabricación de equipo de protección personal (EPP), representa una gran área de oportunidad.

Aunque los virus no se reproducen en ninguna superficie no viva, se ha reportado que la contaminación superficial es muy significativa en la dispersión del SARS-CoV-2, incluso después de la implementación de mecanismos de barrera. Estudios recientes muestran que los coronavirus pueden permanecer viables o infecciosos en superficies de metal, vidrio, madera, telas y plástico durante varias horas o días, independientemente de que la superficie se vea sucia o limpia. Se ha encontrado en superficies de contacto comunes (mesas, camas, manijas de puertas, interruptores de luz, inodoro); en equipo de protección personal, en el aire y también en los pisos y las salidas de los ventiladores en los hospitales (Sean Wei Xiang Ong et al., 2020).

Los tratamientos efectivos contra el coronavirus incluyen vapor y calor. El virus es susceptible a muchos ingredientes activos, como hipoclorito de sodio $(0.1 \%-0.5 \%), 70 \%$ de alcohol etílico, povidona yodada ( $1 \%$ de yodo), cloroxilenol $(0.24 \%), 50 \%$ de isopropanol, $0.05 \%$ cloruro de benzalconio, jabón cresol al $1 \%$ o peróxido de hidrógeno $(0.5 \%-7.0 \%)$, etc. (Dowell et al., 2004). Aun cuando estos compuestos pueden destruir al virus; es prácticamente imposible sanitizar las superficies todo el tiempo y no se garantiza que la superficie no se contamine nuevamente. Ante esta situación, sería ideal que la superficie pudiera repeler a los patógenos o que fuera capaz de autosanitizarse (Sundberg et al., 2015). 
Los nanomateriales son atractivos porque permiten reducir las concentraciones requeridas para generar la actividad inhibitoria. Bajo este contexto, mediante la nanotecnología podrían desarrollarse materiales de prevención primaria con estas características, como los que se mencionan a continuación.

Las nanopartículas (NPs) de varios metales y óxidos metálicos como óxido de zinc $(\mathrm{ZnONPs})_{3}$, óxido cuproso (CuONPs), nanopartículas de plata (AgNPs), yoduro de cobre (CuINPs), nanopartículas de oro en nanopartículas de silicio (AuSiO2NPs) y algunos cationes de amonio cuaternarios QUATs9 pueden funcionar muy bien en la desinfección contra virus.

El mecanismo de acción propuesto de los materiales nano activos dopados contra los virus SARS-CoV-2 es el siguiente: 1) las nanopartículas de Ag inhiben la replicación de los nucleótidos del virus (el principal mecanismo para que sea virulento); 2) se unen a grupos donantes de electrones como el azufre, el oxígeno y el nitrógeno que se encuentran comúnmente en las enzimas dentro del patógeno, haciendo que las enzimas se desnaturalicen y se elimine la fuente de energía en el microorganismo. La plata catiónica $(\mathrm{Ag}+)$ o los QUAT (compuestos cuaternarios de amonio) podrían funcionar (Dhende et al., 2012) para inactivar el SARS-CoV-2 al interactuar con su proteína $S$ en la superficie espiga, así como funciona en el VIH, virus de hepatitis, entre otros (Lu et al., 2008; Elechiguerra et al., 2005). Este compuesto ha sido probado utilizando el bacteriófago (Harada et al., 2018), como el MS2 (poliovirus), teniendo como resultado una eficiencia antiviral de aproximadamente el $99.9 \%$ en solo 2 horas de contacto con la superficie. De igual forma, se ha probado la eficiencia de nanopartículas de óxido de zinc en la inhibición del virus causante de la influenza H1N1 (Ghaffari et al., 2019).

La sinergia de nanopartículas conformadas por un núcleo de cobre y una cubierta de amonio cuaternario tienen una fuerte acción antiviral (Sportelli et al., 2020). Estos nanomateriales podrían aplicarse a los materiales de protección personal y diversas superficies como tela (mascarilla, guantes, batas, cortinas, sábanas), metal (elevadores, manijas de puertas, barandales, transporte público), madera (muebles, pisos y paneles divisorios), concreto (hospitales, clínicas y salas de aislamiento), y plásticos (interruptores, cocina y electrodomésticos.

En el Nova Surface-Care Centre probaron una película antimicrobiana que contiene QUATs y nanopartículas cargadas positivamente como partículas bioactivas dispersadas en polímeros de coordinación. Además, están desarrollando productos químicos activos que podrían inactivar la glucoproteína espiga del coronavirus y a los nucleótidos virales; así como un recubrimiento que puede repeler a esta para anclarse a las superficies. Estas películas tienen una energía superficial ${ }^{3}$ extremadamente baja $(>20 \mathrm{mN} / \mathrm{m})$ que

${ }^{3} \mathrm{~N}$. del E.: La energía superficial se define como la energía necesaria para romper los enlaces intermoleculares. 
se comporta como una superficie omnifóbica que repele al agua y al aceite (Swapan, 2020).

Van Doremalen et al. (2020) probaron la viabilidad del SARS-CoV-2 en diferentes condiciones ambientales (aerosoles, plástico, acero inoxidable, cobre y cartón), encontrando que la viabilidad más larga fue en superficies de acero inoxidable y plástico; la mediana estimada de la actividad media del virus es de aproximadamente $5.6 \mathrm{~h}$ en acero inoxidable y $6.8 \mathrm{~h}$ en plástico. El cobre fue encontrado como eficaz para inactivar el virus en un tiempo más corto. Estos hallazgos coinciden con lo informado sobre el CoV-229E en 2015 (Warnes et al., 2015), donde los bronces que contenían al menos 70\% de cobre fueron muy efectivos al inactivar al CoV-229E, y la tasa de inactivación fue directamente proporcional al porcentaje de cobre. Se demostró que la liberación de iones de cobre y la generación de especies reactivas de oxígeno (ROS) son responsables de la inactivación del coronavirus en superficies de cobre y aleaciones de cobre. Lo anterior coincide con lo reportado por Manuel et al. (2015), en lo que se refiere a la destrucción de partículas virales, en presencia de recubrimientos de cobre. Varios de los biocidas ya aprobados a base de óxido de plata u óxido de zinc están esperando ser probados contra el SARS-CoV-2.

Di Gianvincenzo et al., (2010) reportaron que las nanopartículas híbridas de plata y cobre pueden unirse a la glicoproteína gp120 de la envoltura del VIH e inhibir la infección in vitro por VIH-1 en modelos celulares. Se ha demostrado también que funcionalizando las AgNPs (por ejemplo, con ácido tánico y mercaptoetano-sulfonato) pueden tener la capacidad de prevenir la infección por la inhibición directa de la unión del virus, la penetración y la propagación posterior a la infección.

Otros investigadores como Bhattacharjee et al. (2019), a partir de sus estudios con virus como el ébola, el SARS y el MERS, reportaron que el óxido de grafeno injertado con metal (GO), para la modificación de polímeros no tejidos, demostró tener propiedades antimicrobianas muy efectivas. Los derivados de grafeno pueden ser utilizados como compuestos antimicrobianos con diferentes metales (Ag, Fe, Cu, Zn, etc.) (Nowak et al., 2016) y fotocatalizadores $\left(\mathrm{TiO}_{2}, \mathrm{CdS}, \mathrm{MnS}_{2}\right.$, etc.). $\mathrm{El} \mathrm{GO}$ injertado con nanopartículas metálicas ha sido investigado como un potencial material para la fabricación de EPP. Específicamente, se sabe que los sistemas de nano-plata y cobre cargados en GO son muy efectivos contra los virus con y sin envoltura.

En el caso de las mascarillas que protegen al personal de salud, estas solo bloquean al virus antes de que esté en contacto con la cara. En la Universidad Central de Florida (Smartlighting, 2020), Sudipta Seal, un ingeniero especializado en ciencia de materiales y nanotecnología, junto con el virólogo Griffith Parks están desarrollando, mediante una estrecha colaboración multidisciplinaria, una nanopelícula que atrapa al virus y lo inactiva en segundos. Se trata de nanoestructuras que pueden capturar al virus y entonces desencadenar una reacción química utilizando luz ultravioleta para destruirlo. Faltan por 
realizar pruebas para identificar qué materiales inactivan o atrapan a virus específicos y que tan rápido.

Investigadores chinos (Deng Xiaoci, 2020) han desarrollado un material catalítico que puede absorber y destruir al SARS-CoV-2. En una prueba reciente se reportó una eficiencia de destrucción de virus entre el 96.5 y $99.9 \%$. Desde una perspectiva química, las proteínas, ácido ribonucleico, membranas grasas y otras macromoléculas biológicas contenidas en el virus no son tan estables y son fácilmente hidrolizadas o inactivadas por oxidación, lo cual hace que sean teóricamente factibles de absorber y desactivar.

Asimismo, se han desarrollado nanocompuestos de poliuretano/ $\mathrm{CuO}$, que actúan como un antimicrobiano efectivo, en filtros para purificación de aire (Konda et al., 2020; Ungur y Hruza, 2017); ya que las micropartículas de $\mathrm{CuO}$ son un aditivo más adecuado para la modificación de filtros de poliuretano, reduciendo así los riesgos de nanotoxicidad. Un ejemplo reciente de un sistema de filtrado de aire antiviral para el transporte se basó en el uso de $\mathrm{SiO}_{2}$-AgNPs como material activo contra el bacteriófago MS2 (Krähling et al., 2009).

Por otro lado, de acuerdo con un reporte de Hospimédica (2020), se está desarrollando un nuevo material a base de carbono que puede capturar y destruir virus del tipo SARS-CoV-2. El "filtro de virus activo", en forma de una fina capa de nanotubos de carbono llamada TorStran tiene propiedades de filtración y permeabilidad al aire que le permiten capturar virus libres y los contenidas en gotitas en aerosol aerotransportadas, las cuales constituyen uno de los principales medios de contagio entre el personal médico (Gorbunov, 2020). La filtración y la interrupción del virus tienen lugar simultáneamente, lo que permite que el filtro reduzca el riesgo de infección al eliminar la contaminación del aire. Los investigadores creen que el filtro será particularmente útil en salas de confinamiento, vehículos, hospitales, transporte, áreas de espera y cuartos de hospitales.

Otras opciones de protección de barrera corresponden a nanopartículas que puedan desactivar a los patógenos incluso antes de que entren en el cuerpo. Tal vez, mediante el rociado de soluciones con nanopartículas que inhiban la actividad viral. Se ha reportado que las NP de metales muy pequeños $(<10 \mathrm{~nm})$ pueden atravesar la membrana celular e inhibir la replicación del virus previamente adherido. Por ejemplo, en Milán, Italia, se utilizó una solución que contenía dióxido de titanio y iones de plata para la desinfección de una calle (Nanotech, 2020).

En el Instituto de Investigaciones en Materiales de la UNAM, actualmente se están desarrollando materiales filtrantes con propiedades biocidas intrínsecas, y recubiertos con nanocapas con capacidad antibacteriana y antiviral, los cuales se espera resulten en una alternativa como EPP a partir de insumos disponibles en México. 


\section{Conclusiones}

La COVID-19 es una enfermedad zoonótica con una tasa de mortalidad baja a moderada (Wu et al., 2020). Hoy en día, no existe un tratamiento para la enfermedad, aunque muchos ensayos experimentales están en camino, lo mejor que podemos hacer es desarrollar medidas de prevención a diferentes niveles. Desde los institutos y centros de investigación contando con los avances de la nanotecnología, se pueden realizar propuestas desde un punto de vista terapéutico o para el desarrollo de materiales de protección o conocidos como equipo de barrera. Es importante recalcar que la mayoría de las mascarillas actuales están fabricadas a partir de textiles naturales o sintéticos no-tejidos termofijados que impiden el paso de partículas por diferentes mecanismos de difusión limitada o electrostáticos. Algunas contienen capas con propiedades de hidrofilicidad para mantenerlos secos y pueden contener una capa o filtro de carbón activado. Una de las limitantes actuales para la producción de EPP es la disponibilidad de estos textiles no-tejidos a nivel mundial. Además, estos materiales en sí mismos no presentan propiedades antimicrobianas ni antivirales, solo funcionan como medio filtrante. Por lo tanto, mediante la nanotecnología sería posible perfeccionar textiles naturales o sintéticos con propiedades funcionales, tales como hidrofílicos, antiestáticos e incluso antibacterianos y/o antivirales. Los nanomateriales son atractivos porque permiten reducir las concentraciones terapéuticas requeridas para presentar la actividad inhibitoria. Finalmente, es recomendable contar con medidas de contención y políticas públicas para actuar ante las conductas humanas (granjas que se intensifican, la deforestación que pone a más animales en contacto con más gente, la cría intensiva que hacina los animales) que dan mayor oportunidad a los virus de combinarse y llegar a los humanos.

\section{Referencias}

Andersen, K., Rambaut, A., Lipkin, W., Holmes. E. y Garry, R. (2020). The proximal origin of SARS-CoV-2. Nature Medicine, 26: 450-455. https://doi.org/10.1038/ s41591-020-0820-9

Anderson, L., Schneider, E. (2012). Goldman's Cecil Medicine. Elsevier. https://doi. org/10.1016/C2009-0-42832-0

Bhattacharjee, S., Joshi, R., Chughtai, A. A., Macintyre, C. R. (2019). Graphene modified multifunctional personal protective clothing. Adv. Mater. Interfaces, 6, 1900622. https://doi.org/10.1002/admi.201900622

Biao He, Yuzhen Zhang, Lin Xu, Weihong Yang, Fanli Yang, Yun Feng, Lele Xia, Jihua Zhou, Weibin Zhen, Ye Feng, Huancheng Guo, Hailin Zhang, Changchun Tu. (2014). Identification of diverse alphacoronaviruses and genomic characterization of a novel severe acute respiratory syndrome-like coronavirus from bats in China. Journal of Virology, 88(12): 7070-7082. S.

https://doi.org/10.1128/JVI.00631-14 
BioOptics World. (2020). UV light-activated coating for masks could trap, kill Covid-19. https://www.bioopticsworld.com/biophotonics-tools/article/14173860/ uv-lightactivated-coating-for-masks-could-trap-kill-covid19

Broglie, B. Alston, C. Yang, L. Ma, A. F. Adcock, W. Chen, L. Yang, (2015). Antiviral activity of gold/copper sulfide core/shell nanoparticles against human norovirus virus-like particles. PLOS ONE, 10: e0141050. https://doi.org/10.1371/journal. pone.0141050

Callaway, E. y David Cyranoski. (2020). China coronavirus: Six questions scientists are asking. Nature, 577: 605-607. https://doi.org/10.1038/d41586-020-00166-6

Carroll, K., Jeffery A. Hobden, Steve Miller, Stephen A. Morse, Timothy A. Mietzner, Barbara Detrick, Thomas G. Mitchell, James H. McKerrow, Judy A. Sakanari. (2016). Microbiología Médica. Mc Graw Hill.

Chen, K.T., D. Ray, Y.-H. Peng, Y.-C. Hsu. (2013). Preparation of Cu-Ag core-shell particles with their anti-oxidation and antibacterial properties. Current Applied Physics, 13: 1496-1501.

Colimon K. Niveles de Prevención. http://issuu.com/viejo03/docs/nameb7c044

Cui, J., Li, F., Shi, Z. (2019). Origin and evolution of pathogenic coronaviruses. Nature Reviews Microbiology, 17:181-192. https://doi.org/10.1038/s41579-018-0118-9

Deng Xiaoci. (2020). China researchers develop Covid-19 virus-fighting material. Globaltimes.cn. https://www.globaltimes.cn/content/1184240.shtml

Dhende, V. P., I.R. Hardin, I. R., J. Locklin, J. (2012). Durable antimicrobial textiles: types, finishes and applications. En: P. A. Annis (ed.), Understanding and improving the durability of textiles. Woodhead Publishing, 145-173.

Di Gianvincenzo, P., Marradi, M., Martínez-Ávila, O. M., Bedoya, L. M., Alcamí, J., Penadés, S. (2010). Gold nanoparticles capped with sulfate-ended ligands as anti-HIV agents. Bioorganic Med. Chem. Lett., 20: 2718-2721. https://doi.org/10.1016/j. bmcl.2010.03.079

Dinca, P., B. Butoi, M. Lungu, C. Porosnicu, I. Jepu, C. Staicu, C. Lungu, A. Niculescu, I. Burducea, O. Trusca, M. Diaconu, I. Cretescu, G. Soreanu. (2020). Antibacterial efficiency of stainless-steel grids coated with $\mathrm{Cu}-\mathrm{Ag}$ by thermionic vacuum arc method. Coatings, 10: 322. https://doi.org/10.3390/coatings10040322

Dowell, S. F., Simmerman, J. M., Erdman, D. D., Wu, J. -S. J., Chaovavanich,. A., Javadi, M., Yang, J.-Y., Anderson, L. J., Tong, S., Ho, M. S. (2004). Severe acute respiratory syndrome coronavirus on hospital surfaces. Clin. Infect. Dis. 39: 652-657. https://doi.org/10.1086/422652

Elechiguerra, J. L., Burt, J. L., Morones, J. R., Camacho-Bragado, A., Gao, X., Lara, H. H., Yacamán, M. J. (2005). Interaction of silver nanoparticles with HIV-1. Nanobiotechnology, 3(6). https://doi.org/10.1186/1477-3155-3-6

Ghaffari, H., Tavakoli, A., Moradi, A., Tabarraei, A., Bokharaei-Salim, F., Zahmatkeshan, M., Farahmand, M., Javanmard, D., S. J. Kiani, M. Esghaei, V. PirhajatiMahabadi, S. H. Monavari, A. Ataei-Pirkooh. (2019). Inhibition of H1N1 influenza virus infection by zinc oxide nanoparticles: another emerging application of nanomedicine. Journal of Biomedical Science, 26: 70. https://doi. org/10.1186/s12929-019-0563-4 
Global Preparedness Monitoring Board, GPMB. (2019). A world at risk. Annual report on global preparedness for health emergencies. Global Preparedness Monitoring Board of the World Health Organization, Geneva. https:/apps.who.int/gpmb/assets/ annual_report/GPMB_annualreport_2019.pdf?utm_source=mandiner\&utm_ medium=link\&utm_campaign=mandiner_202004

Gorbunov, B. (2020). Aerosol particles laden with Covid-19 travel over $30 \mathrm{~m}$ distance. In press. https://doi.org/10.20944/preprints202004.0546.v1

Harada, L. K. E. C. Silva, W. F. Campos, F. S. del Fiol, M. Vila, K. Dąbrowska, V. N. Krylov, V. M. Balcão. (2018). Biotechnological applications of bacteriophages: State of the art. Microbiological Research, 212-213: 38-58. https://doi.org/10.1016/j. micres.2018.04.007

Hoffmann, M. et al. (2020). SARS-CoV-2 cell entry depends on ACE2 and TMPRSS2 and is blocked by a clinically-proven protease inhibitor. Cell, https://doi.org/10.1016/j. cell.2020.02.052

Hospimedica Daily Clinical News. (2020). Revolutionary new carbon-based material captures and destroys coronavirus. Mayo, 2020. https://www.hospimedica.com/ covid-19/articles/294782226/index.php

Huang, C., Wang, Y., Li, X., Ren, L., Zhao, J., Hu, Y., Zhang, L., Fan, G., Xu, Gu, X., Cheng, Z., Yu, T., Xia, J., Wei, Y., Wu, W., Xie, X., Yin, W., Li, H., Liu, M., Xiao, Y., Gao, H., Guo, L., Xie, J., Wang, G., Jiang, R., Gao, Z., Jin, Q., Wang, J., Cao, B. (2020). Clinical features of patients infected with 2019 novel coronavirus in Wuhan, China. The Lancet, 395: 497-506. https://doi.org/10.1016/S01406736(20)30183-5

Huang, H., Fan, M. Li, H. -L. Nie, F. -B. Wang, H. Wang, R. Wang, J. Xia, X. Zheng, X. Zuo, J. Huang. (2020). Covid-19: A call for physical scientists and engineers. ACS Nano. 14: 3747-3754. https://doi.org/10.1021/acsnano.0c02618

Humphreys, M. (2018). The influenza of 1918: Evolutionary perspectives in a historical context. Evolution, Medicine and Public Health, 1: 219-229. https://doi. org/10.1093/emph/eoy024

Ji, W., Wang, W., Zhao, X., Zai J., Li, X. (2020). Cross-species trasnmission of the newly identified coronavirus 2019-n-CoV. Journal of Medical Virology, 433440. https://doi.org/10.1002/jmv.25682

Khalaj, M. Kamali, Z. Khodaparast, A. Jahanshahi. (2018). Copper-based nanomaterials for environmental decontamination - An overview on technical and toxicological aspects. Ecotoxicology and Environmental Safety, 148: 813-824. https://doi.org/10.1016/j.ecoenv.2017.11.060

Konda, A. Prakash, G. A. Moss, M. Schmoldt, G. D. Grant, S. Guha. (2020). Aerosol filtration efficiency of common fabrics used in respiratory cloth masks. ACS Nano. https://doi.org/10.1021/acsnano.0c03252

Krähling, V., Stein, D. A., Spiegel, M., Weber, F., Mühlberger, E. (2009). Severe acute respiratory syndrome coronavirus triggers apoptosis via protein kinase $\mathrm{R}$ but is resistant to its antiviral activity. J. Virol, 83: 2298-2309. https://doi.org/10.1128/ JVI.01245-08

Leavell, S. y Clark, E. G. (1976). Medicina preventiva. San Pablo: McGraw-Hill. 
Ledford, H. (2020). How does Covid-19 kill? Uncertainty hampers doctor's ability to choose treatments. Nature, 580: 311-312. https://doi.org/10.1038/d41586020-01056-7

Liu, P., Chen, W., Chen J. (2019). Viral metagenomics revealed sendai virus and coronavirus infection of Malayan pangolins (Manis javanica). Viruses, (11)11: 979. https://doi.org/10.3390/v11110979

Lu, R. W. Y. Sun, R. Chen, C. K. Hui, C. M. Ho, J. M. Luk, G. K. K. Lau, C. M. Che. (2008). Silver nanoparticles inhibit hepatitis B virus replication. Antiviral Ther, 13.

Ma, J. (2020). Coronavirus: China's first confirmed Covid-19 case traced back to November 17. South China Morning Post. Marzo 13, 2020. https://www.scmp.com/ news/china/society/article/3074991/coronavirus-chinas-first-confirmed-covid19-case-traced-back

MacLachlan, N., y Dubovi, E. (2011). Fenner's veterinary, virology. Elsevier. https:// doi.org/10.1016/C2009-0-01816-9

Manuel, C. S., M. D. Moore, L. A. Jaykus. (2015). Destruction of the capsid and genome of GII.4. Human norovirus occurs during exposure to metal alloys containing copper. Applied and Environmental Microbiology, 81: 4940. K. E. Wommack (ed.). https://doi.org/10.1128/AEM.00388-15

Masters, Paul. (2006). The molecular biology of coronaviruses. Advances in Virus Research, 66: 193-292. https://doi.org/10.1016/S0065-3527(06)66005-3

Menachery, Vineet D., Boyd, L., Yount, Jr., Kari Debbink, Sudhakar Agnihothram, Lisa E. Gralinski, Jessica A. Plante, Rachel L. Graham, Trevor Scobey, Xing-Yi Ge, Eric F. Donaldson, Scott H. Randell, Antonio Lanzavecchia, Wayne A. Marasco, Zhengli-Li Shi y Ralph S. Baric. (2015). A SARS-like cluster of circulating bat coronaviruses shows potential for human emergence. Nature Medicine, 21(12): 1508-1513. https://doi.org/10.1038/nm.3985

Mesel-Lemoine, M., Jean Millet, Pierre-Olivier Vidalain, Helen Law, Astrid Vabret, Valérie Lorin, Nicolas Escriou, Matthew L. Albert, Béatrice Nal, y Frédéric Tangy. (2012). A human coronavirus responsible for the common cold massively kills dendritic cells but not monocytes. Journal of Virology, 86(14): 75777587. https://doi.org/10.1128/JVI.00269-12

Molar, R. Candanosa. (2020). Here's how nanoparticles could help us get closer to a treatment for Covid-19. News at Northeastern. Marzo. https://news.northeastern.edu/2020/03/04/heres-how-nanoparticles-could-help-us-get-closerto-a-treatment-for-covid-19/

Nanotech. (2020). https://statnano.com//news/67531/Coronavirus-Nanotech-SurfaceSanitizes-Milan-with-Nanomaterials-Remaining-Self-sterilized-for-Years

Nowak, A., J. Szade, E. Talik, M. Zubko, D. Wasilkowski, M. Dulski, K. Balin, A. Mrozik, J. Peszke. (2016). Physicochemical and antibacterial characterization of ionocity Ag/Cu powder nanoparticles. Materials Characterization, 117: 9-16.

OMS. (2008). La atención primaria de la salud. Más necesaria que nunca. Informe sobre la salud en el mundo. http://www.who.int/whr/2008/08_report_es.pdf 154 pp.

Pulido Salgado, M. (2020). Mantenerse bien informado: la mejor estrategia contra el SARS-CoV-2. https://www.investigacionyciencia.es/noticias/mantenerse-bien- 
informado-la-mejor-estrategia-contra-el-sars-cov-2-18416

Regalado, A. (2020). La vacuna contra el coronavirus no estará lista hasta 2021 como mínimo. MIT Technology Review. Marzo.

Reglamento Sanitario Internacional. Organización Mundial de la Salud (OMS). (2005). https://www.who.int/ihr/IHR_2005_es.pdf

Sean Wei Xiang Ong, Yian Kim Tan, Po Ying Chia, Tau Hong Lee, Oon Tek Ng, Michelle Su Yen Wong y Kalisvar Marimuthu. (2020). Air, surface environmental, and personal protective equipment contamination by severe acute respiratory syndrome coronavirus 2 (SARS-CoV-2) from a symptomatic patient. JAMA. 323816): 1610-1612. https://doi.org/10.1001/jama.2020.3227

Sportelli, M. C., Longano, D., Bonerba, E., Tantillo, G., Torsi, L., Sabbatini, L., Cio, N., Ditaranto, N. (2020). Electrochemical preparation of synergistic nanoantimicrobials. Molecules, 25(1): 49. https://doi.org/10.3390/molecules25010049

Stephen N. J. Korsman, Gert U. van Zyl, Louise Nutt, Monique I. Andersson, Wolfgang Preiser. (2012). Human coronaviruses. Virology. https://doi.org/10.1016/ B978-0-443-07367-0.00040-9

Sundberg, K., Champagne, V., McNally B., Helfritch D., S. R. (2015). Effectiveness of nanomaterial copper cold spray surfaces on inactivation of influenza A virus. J. Biotechnol. Biomater, 5: 205. 14040-14045. https://doi.org/10.1073/pnas.0506735102

Swapan Kumar Ghosh. (2020). Anti-viral surface coating to prevent spread of novel coronavirus (Covid-19) through touch. https://www.coatingsworld.com/contentmicrosite/cw_covid-19/2020-04-15/anti-viral-surface-coating-to-preventspread-of-novel-coronavirus-covid-19-through-touch

Terris, M. (1990). Public health policy for the 1990s. Annu. Rev. Public Health, 11: 39-51.

Tsan-Yuk, T., Ho-Hin, M., Zhu, H., Tong, Y., Ni, X., Liao, Y., Wei, W., Cheung, W., Li, W., Li, L., Leung, G., Holmes, E., Hu, Y y Guan, Y. (2020). Identifying SARS-CoV-2 related coronaviruses in Malayan pangolins. Nature. https://doi.org/10.1038/ s41586-020-2169-0

Tse, L., Meganck, R., Graham, R., Baric, R. (2020). The current and future state of vaccines, antivirals and gene therapies against emerging coronaviruses. Frontiers in Microbiology, 11. https://doi.org/10.3389/fmicb.2020.00658

Ungur, G., Hruza, J. (2017). Modified polyurethane nanofibers as antibacterial filters for air and water purification. RSC Adv., 7: 49177-49187. https://doi. org/10.1039/C7RA06317B

Valodkar, M., S. Modi, A. Pal, S. Thakore. (2011). Synthesis and anti-bacterial activity of $\mathrm{Cu}, \mathrm{Ag}$ and $\mathrm{Cu}-\mathrm{Ag}$ alloy nanoparticles: A green approach. Materials Research Bulletin, 46: 384-389. https://doi.org/10.1016/j.materresbull.2010.12.001

Van Doremalen, N., Bushmaker, T., Morris, D. H., Holbrook, M. G., Gamble, A., Williamson, B. N., Tamin, A., Harcourt, J. L., Thornburg, N. J., Gerber, S. I. et al. (2020). Aerosol and surface stability of SARS-CoV-2 as compared with SARS-CoV-1. N. Engl. J. Med.382(16): 1564-1567. https://doi.org/10.1101/2020.03.09.20033217

Vignolo, Julio, Mariela Vacarezza, Cecilia Alvarez, Alicia Sosa. (2011). Niveles de atención, de prevención y atención primaria de la salud. Arch Med Interna, 33(1): 7-11. 
Vincent, M., R. E. Duval, P. Hartemann, M. Engels-Deutsch. (2018). Contact killing and antimicrobial properties of copper. Journal of Applied Microbiology, 124: 1032-1046. https://doi.org/10.1111/jam.13681

Warnes, S. L., Little, Z. R., Keevil, C. W. (2015). Human coronavirus 229E remains infectious on common touch surface materials. American Society for Microbiology. 6(6): 1-10. https://doi.org/10.1128/mBio.01697-15

Weiss, S. y Leibowitz, J. (2011). Coronavirus pathogenesis. Advances in Virus Research, 81:85-164. https://doi.org/10.1016/B978-0-12-385885-6.00009-2

Wu, F., Zhao, S., Yu, B., Chen, Y. M., Wang, W., Song, Z. G., Hu, Y., Tao, Z., W., Tian, J. H., Pei, Y. Y. et al. (2020). A new coronavirus associated with human respiratory disease in China. Nature. https://doi.org/10.1038/s41586-020-2008-3

Wu, Y., Chen, Ch., Chan, Y. (2020). The outbreak of Covid-19: An overview. Journal of the Chinese Medical Association. https://doi.org/10.1097/JCMA.0000000000000270

Yang, K., L. Chen, Y. -C. Chen, L. Kang, J. Yu, Y. Wang, C. Lu, T. Mashimo, A. Yoshiasa, C. -H. Lin. (2019). Homogeneously alloyed nanoparticles of immiscible $\mathrm{Ag}-\mathrm{Cu}$ with ultrahigh antibacterial activity. Colloids and Surfaces B: Biointerfaces, 180: 466-472. https://doi.org/10.1016/j.colsurfb.2019.05.018

Zhang, T., Wu, Q., Zhang, Z. (2020). Pangolin homology associated with 2019-nCoV. bioRxiv. Preprint. https://doi.org/10.1101/2020.02.19.950253

Zhou, P., Yang, X. L., Wang, X. G., Hu, B., Zhang, L., Zhang, W., Si, H. R.,Zhu, Y., Li, B., Huang, C.L. et al. (2020). A pneumonia outbreak associated with a new coronavirus of probable bat origin. Nature, 579(7798): 270-273. https://doi.org/10.1038/ s41586-020-2012-7 